\title{
Treatment patterns in patients using triptan and prophylactic medication: an analysis of clinical practice prior to the introduction of CGRP antagonists
}

This article was published in the following Dove Press journal:

Journal of Pain Research

\author{
Carola A Huber' \\ Reto Agosti ${ }^{2}$ \\ Markus Näpflin' \\ Eva Blozik ${ }^{1,3}$ \\ 'Department of Health Sciences, Helsana \\ Insurance Group, Zürich, Switzerland; \\ ${ }^{2}$ Headache Center Hirslanden, \\ Hirslanden Hospital Group, Zürich, \\ Switzerland; ${ }^{3}$ Department of Medicine, \\ University of Medical Centre Freiburg, \\ Freiburg, Germany
}

Purpose: The newly developed calcitonin gene-related peptide (CGRP) antagonists were recently launched on the US and European market, with Switzerland as the second country worldwide. To enable forthcoming comparisons with established migraine therapy, the aim of this study was to provide a comprehensive picture of migraine (prophylactic) treatment patterns. Recent data in daily clinical practice are lacking.

Patients and methods: This population-based cohort study included enrollees from a Swiss Healthcare Insurance Database with at least one triptan prescription in 2015. Treatment patterns were defined by assessing subsequent triptan and prophylactic medication use (after index prescription for triptan) within the following year, divided into four quarters. Results: Triptans were used by 10,090 patients (1.3\%) in 2015. Most of them used triptan only $(82.6 \%), 12.9 \%$ changed the treatment between triptan and prophylactics, and $4.5 \%$ received both in combination within 1year. Among triptan users with $\geq 1$ prophylactic prescription in the first quarter, $48.6 \%$ used beta-blockers (BB), 40.7\% "other prophylactics than BB (eg, topiramate)", and 10.7\% "a combination of both". Most patients who received both BB and other prophylactics in the first quarter used this drug combination continuously over all four quarters.

Conclusion: This study provides comprehensive data on treatment patterns prior to the introduction of a new drug class in migraine therapy. The majority of triptan users had no prophylactic medication therapy; however, a small, but relevant group used BB and other prophylactics concurrently in all quarters. Findings quantify the population in potential need for optimized migraine therapy, ie, the potential target population of the novel CGRPtargeted drugs.

Keywords: innovation, headache, migraine, preventive medication, drugs, real-world data

\section{Introduction}

Triptans (selective 5HT [serotonin] receptor agonist) were recommended as goldstandard therapy in international guidelines for patients with acute migraine attacks. $^{1,2}$ Since the introduction of the triptans in the early nineties, overall seven active ingredients within this therapeutic group are available as prescription drugs in most countries in Europe (including Switzerland) and in the USA: sumatriptan, naratriptan, zolmitriptan, rizatriptan, almotriptan, eletriptan, and frovatriptan. Numerous persons with acute migraine can be adequately treated by triptans alone, but a relevant proportion need prophylactic interventions, as their attacks are 
either very frequent or are insufficiently controlled by acute therapy. ${ }^{3}$ Several drugs, such as beta-blockers and others, have been shown to reduce attack frequency in some people. ${ }^{3,4}$ However, all these drugs may be connected with adverse effects, contraindications, or intolerances, and patient acceptance of these drugs is limited. Thus, specific patient populations with severe migraine are currently lacking effective therapies, and new approaches for the management of migraine therapy for these patients are needed. ${ }^{3,5}$

Recent clinical trials provide evidence that calcitonin gene-related peptide (CGRP), a transmitter in the central and peripheral nervous system, play an important role in the development, maintenance, and chronicity of migraine and could be a potential target therapy for migraine prevention. $^{6-8}$ CGRP is a 37 -amino acid neuropeptide, belongs to the calcitonin family and is known as one of the strongest vasodilators. CGRP levels are increased during migraine attacks, and thus blocking of the CGRPinduced vasodilatation is expected to reduce symptoms of migraine. ${ }^{9,10}$ The STRIVE study, for example, compared a CGRP receptor antagonist (erenumab) as a monthly subcutaneous injection with placebo in 955 patients who had reported 8.3 migraine attacks per month before the study began. ${ }^{6}$ Erenumab could not completely prevent further attacks, but could reduce their average number by 3.2 per month in the $70 \mathrm{mg}$ dose and by 3.7 per month in the $140 \mathrm{mg}$ dose compared to a decrease of 1.8 attacks per month in the placebo group. Erenumab was launched successfully, and galcanezumab and fremanezumab received FDA approval (October 2018). However, in order to approve a (potential) innovation in the migraine drug market, it is important to evaluate the present clinical practice in migraine acute and prophylactic treatment and consequently to compare it with the new therapeutic approach. Understanding current triptan user behavior and usage patterns within prophylactic treatment enables a prospective comparative analysis before and after the introduction of the new drug class, CGRP antagonists (blocking either CGRP ligands or receptors). However, within the last decade, only few studies provided a precise and comprehensive description on prevalence, extent, and patterns of acute and prophylactic migraine drug use. ${ }^{11-13}$ Triptan use was investigated by some previous clinical and pharmacoepidemiological studies, indicating a range of prevalence from less than $1 \%$ to over $2 \%{ }^{14,15}$ Some studies included small sample sizes, and no study has recently assessed the prevalence of triptan. ${ }^{11,14-17}$ One of the recently published studies was based on data from 2007 and contributed to conflicting results as findings revealed - in contrast to prior findings - a rather low proportion of triptan user of about only half a percent. ${ }^{15}$

In view of the forthcoming CGRP antagonists as well as the lack of data on the present migraine drug therapy in clinical practice, a comprehensive overview of the recent pattern of triptan and, especially, prophylactic use is needed for future comparisons between the established migraine therapy and new approaches. Triptan users, suffering from acute severe migraine attacks, represent the target population for future potential CGRP antagonist consumer. Therefore, the aim of the present study was to provide a detailed picture of the pattern of triptan and prophylactic use by analyzing treatment patterns of triptan user, especially in terms of combination therapy and changing in migraine-specific medication (triptans and prophlactics) therapy over time in daily clinical practice.

\section{Materials and methods}

\section{Study design and population}

This analysis is a retrospective, population-based cohort study of a longitudinal patient-level-linked database containing claims data and anonymized records of mandatory health-insured persons in Switzerland (Helsana Group). Helsana is one of the largest Swiss health insurance groups whose database includes pharmacy, medical, and health services claims of about 1.2 million patients (around $15 \%$ of the entire Swiss population) and is considered approximately representative to the general population. All Swiss residents are obligated to have a basic health insurance, which can be acquired on private market of health insurers. The health insurance market is regulated by federal authorities, and every insurer is obligated to offer basic health insurance to every resident. The basic health insurance saves medical treatment that is considered as appropriate, clinically effective, and cost-effective. Insured persons, however, have co-payments including an annual deductible, which ranges from CHF 300 to a maximum of 2,500 and can be chosen by the insured person, and an annual amount of $10 \%$ of the incurred costs (maximum of CHF 700).

Subjects were seen as eligible for inclusion when they had at least one prescription of triptan in 2015, were continuously covered by Helsana and aged $\geq 18$ years. We selected persons with initiated triptan prescription in 2015 and followed them 12 months from the date of index 
prescription (Figure 1). The following active ingredients were included: sumatriptan, naratriptan, zolmitriptan, rizatriptan, almotriptan, eletriptan, and frovatriptan.

\section{Definition of treatment patterns}

To monitor the treatment patterns of the patients using triptans, we additionally evaluated the migraine-related medication use (triptans, prophylactics) of the patients within the follow-up period. For each quarter after index prescription (Q1-Q4), we described the received medications, whereby triptan use in $\mathrm{Q} 1$ was preconditioned: triptan only, prophylactics only, or combination (triptan and prophylactics). Based on this analysis, we summarized the data and constructed the following categories: use of trip$\tan$ only in $\geq 1$ quarter ("Triptan only", Group 1), use of triptan and prophylactics combined in $\geq 1$ quarter ("Triptan and prophylactics", Group 2), and mixed and changed use of triptans and prophylactics ("Change in treatment", Group 3). Prophylactic medication use, assessed in each quarter, comprised the following active ingredients: sibelium, topiramate, propranolol, metoprolol, botulinum toxin, and others (bisoprolol, amitriptyline, and valproic acid).

Moreover, a prophylactic subgroup analysis was performed to represent patients with preventive medication, which included subjects who had at least one prescription of prophylactics in Q1. In this secondary analysis, we investigated the treatment patterns of patients using prophylactics (within the followed-period, Q1-Q4), by subdividing into the type of prophylactic drug classes. All patients who have received prophylaxis within the four quarters were defined as Group A "Prophylactics other than beta-blockers", as Group B "Beta-blockers, no other prophylactics", and as Group C "Combination of prophylactic treatment (beta-blockers and other prophylactics)". Additionally, we examined further drug information including the number of packages dispensed within the 12 months after index prescription among the prophylactic subgroup sample.

\section{Measures and data analysis}

Patients' baseline characteristics were assessed at index date, including gender, age (groups), and region of residence. Clinical characteristics comprised previous prescriptions of migraine-specific medication (triptans and prophylactics), the use of acute medication within the following 12 months after index date (analgesics, antiemetics), and patients' comorbidity status measured by pharmacy-based proxy diagnoses in the previous year. Proxy diagnoses were derived from prescribed drug data. Every drug can be assigned to its WHO Anatomical Therapeutic Chemical (ATC) code. The WHO ATC code of the drug describes its active ingredient and can be assigned to related chronic diseases (for example, oral antidiabetic drug and insulin use [ATC code A10A/B] as proxy diagnosis for diabetes mellitus). ${ }^{18}$

Patient characteristics of triptan and prophylactic user were analyzed using descriptive statistics: categorical variables were presented as absolute numbers of subjects and percentages, continuous data as mean \pm SDs. We compared nominal and categorical variables of the different (prophylactic) treatment groups by using Pearson's Chisquared test (nominal) and continuous data by KruskalWallis test for >2-groups-comparisons (categorical).

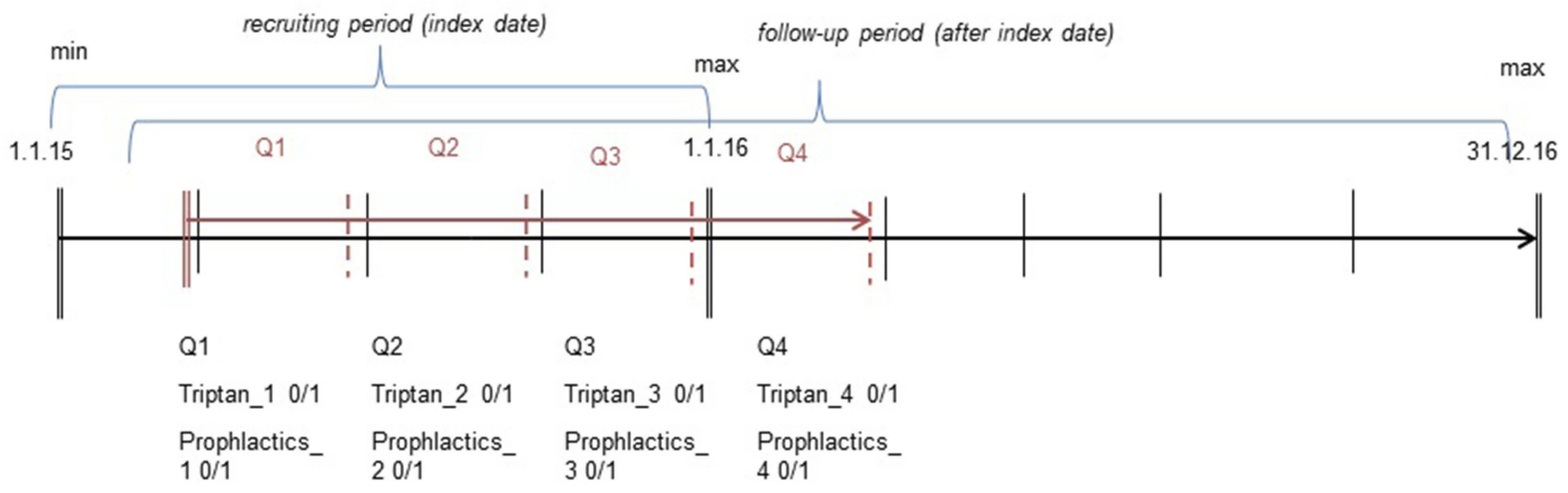

Figure I Study design for selecting the patient cohort (study flow). This figure displays an example of a patient, who received the first triptan prescription in 2015 (index date) and were followed for four quarters. 
Statistical significance was determined at the 0.05 level. All analyses were done using the statistical program $\mathrm{R}$ version 3.2.0 ( $\mathrm{R}$ Development Core Team 2015). According to the national ethical and legal regulation (the Swiss Federal Law of data protection), an ethical approval and patient consent were not needed.

\section{Results}

\section{Sociodemographic and clinical}

\section{characteristics}

This cohort of triptan users included 10,090 subjects (Table 1), which corresponds with a percentage of $1.3 \%$ of the population using triptans out of the total study population of 749,092 . There was a significantly higher proportion of women than men $(81.1 \%$ vs $18.9 \%)$ and a mean age of $48.1(\mathrm{SD} \pm 14.8)$ in the study cohort. Twothirds $(66.0 \%)$ of the sample with migraine were between 35 and 64 years old, and therefore with a lower percentage of older patients ( $>64$ years: $14.0 \%$ ). Whereas more than half $(53.9 \%)$ of the patients used triptans in the previous

Table I Baseline characteristics of the study population at index triptan prescription (QI)

\begin{tabular}{|l|l|}
\hline Characteristics & $\begin{array}{l}\text { N (\%); } \\
\text { N= I 0,090 }\end{array}$ \\
\hline $\begin{array}{l}\text { Gender } \\
\text { Female }\end{array}$ & $8,181(81.1 \%)$ \\
Male & $1,909(18.9 \%)$ \\
\hline Mean age (SD) & $48.1(14.8)$ \\
\hline Age groups (in years) & \\
I8-24 & $673(6.7 \%)$ \\
$25-34$ & $1,337(13.3 \%)$ \\
$35-44$ & $2,024(20.1 \%)$ \\
$45-54$ & $2,715(26.9 \%)$ \\
$55-64$ & $1,922(19.0 \%)$ \\
$65-74$ & $1,033(10.2 \%)$ \\
$75-84$ & $331(3.3 \%)$ \\
$>84$ & $55(0.5 \%)$ \\
\hline Triptan use (previous year) & $5,437(53.9 \%)$ \\
\hline Prophylactic use (previous year) & $1,490(14.8 \%)$ \\
\hline Prophylactic use (within the following I2 months) & $1,752(17.4 \%)$ \\
\hline Acute medication use (within the following I2 & \\
months) & $5,668(56.2 \%)$ \\
Analgesics & $263(2.61 \%)$ \\
\hline Antiemetics & \\
\hline
\end{tabular}

Abbreviation: Q, quarter. year (incident cases of triptan use: $n=4,653$ ), $85.0 \%$ of the patients had no prescription of prophylactics in the year before. Within the 12-month follow-up period, $17.4 \%$ of the triptan user were prescribed prophylactic treatment as well. Acute medication as analgesics received approximately $56 \%$ of the triptan user.

\section{Treatment patterns in the follow-up period}

Table 2 presents the migraine-specific drug use for each quarter (Q1-Q4). Overall, three medication groups were defined for each quarter, whereby triptan use in Q1 was preconditioned: triptan only, prophylactics only, or combination (triptan and prophylactics). Based on this analysis, we summarized the results and identified 8,338 patients with triptan only in $\geq 1$ quarter (Group 1: 82.6\%), 454 patients with triptans and prophylactics in combination in $\geq 1$ quarter (Group 2: 4.5\%), and 1,298 patients with a change in treatment (Group 3: 12.9\%; Table 3). The highest proportion of women (84.7\%) and of patients over 64 years $(16.1 \%)$ were observed in the patient Group 3. About three-quarters of the patients in treatment Group 2 and Group 3 were suffering from more than two comorbid conditions, nearly $15 \%$ from exactly 2 conditions and only $3-4 \%$ had no comorbidity. In contrast, the triptan-only group (1) included about $14 \%$ with no comorbidity, and consequently with a lower percentage of patients with more than two comorbid conditions $(51.5 \%)$. In the previous year, the majority of patients have already used triptans in all treatment groups, but prophylactics received mostly patients who were also prescribed preventive medication in the baseline year. Patients of all three treatment groups were mostly prescribed analgesics as acute medication.

\section{Active substance in prophylactic treatment}

Figure 2 depicts the type of prophylactic treatment in patients who had at least one prescription in Q1 $(n=1,246)$. About $40.7 \%(n=507)$ of the prophylactic users received "other prophylactics than beta-blockers (Group A)" (eg, valporic acid or topiramate), almost 48.6\% ( $\mathrm{n}=606$ ) used "beta-blockers (Group B)", and $10.7 \%(n=133)$ had a "combination of both prophylactic treatments (Group C)". In each prophylactic group, the following proportions of patients used the medication at least in one-quarter: Group A “59.2\%”, Group B “69.8\%”, 
Table 2 Treatment patterns of patients with triptan use in QI (per quarter)

\begin{tabular}{|c|c|c|c|c|}
\hline QI & Q2 & Q3 & Q4 & $\mathbf{N}(\%)$ \\
\hline Triptan only & - & - & - & $3,4 \mid 4(33.8 \%)$ \\
\hline Triptan only & Triptan only & Triptan only & Triptan only & I,835 (I8.2\%) \\
\hline Triptan only & - & Triptan only & - & $592(5.9 \%)$ \\
\hline Triptan only & Triptan only & - & - & 591 (5.9\%) \\
\hline Triptan only & - & - & Triptan only & $536(5.3 \%)$ \\
\hline Triptan only & Triptan only & - & Triptan only & $510(5.1 \%)$ \\
\hline Triptan only & Triptan only & Triptan only & - & 453 (4.5\%) \\
\hline Triptan only & - & Triptan only & Triptan only & 407 (4.0\%) \\
\hline Combination & Combination & Combination & Combination & $212(2.1 \%)$ \\
\hline Combination & - & - & - & $152(1.5 \%)$ \\
\hline Combination & Prophylactics only & Prophylactics only & Prophylactics only & 101 (I.0\%) \\
\hline Combination & Triptan only & Triptan only & Triptan only & $53(0.5 \%)$ \\
\hline Triptan only & Triptan only & Triptan only & Combination & 47 (0.5\%) \\
\hline Combination & Prophylactics only & - & - & 36 (0.4\%) \\
\hline Combination & Combination & Combination & Triptan only & 36 (0.4\%) \\
\hline Triptan only & - & Prophylactics only & - & 36 (0.4\%) \\
\hline Combination & Combination & Prophylactics only & Combination & 32 (0.3\%) \\
\hline Triptan only & Combination & Combination & Combination & 31 (0.3\%) \\
\hline Triptan only & Prophylactics only & - & - & $29(0.3 \%)$ \\
\hline Combination & Prophylactics only & Prophylactics only & - & $27(0.3 \%)$ \\
\hline Other combinations & Other & Other & Other & 960 (9.5\%) \\
\hline
\end{tabular}

Abbreviation: $\mathrm{Q}$, quarter.

and Group C " $45.2 \%$ ". Whereas the combi-group (Group C) had only a low proportion of single user (Q1; 6.8\%), Group A and Group B showed a very high proportion of patients, who used the drug only in the first quarter (Group A: 27.2\%; Group B: 23.1\%). Within these groups, for example, more than half $(54.8 \%)$ of the "combi-users" received both drugs throughout all four quarters; for users of beta-blockers, this was only $30.2 \%$. Additionally, when calculated the number of switcher within the prophylactic treated group (beta-blocker and non-beta-blockers; $n=133,10.7 \%$ ), we could observe that among these patients only 48 (36.1\%) switched exactly once from beta-blockers to non-beta-blockers (or vice versa) within 12 months from index date (results not shown). The other 85 patients $(63.9 \%)$ switched from one prophylactic medication to another medication multiple times.

Table 4 shows the individual active substances which were used in the respective prophylactic groups. Topiramate was prescribed by a majority in Group A (other prophylactics than beta-blockers, 61.7\%). Botulinum toxin, on the other hand, was only used in a total of 22 persons, and for beta-blockers "metoprolol" was the most prescribed active ingredient in Group B (beta-blockers, no other prophylactics: 57.8\%) and Group
C (combination of prophylactic treatments: $53.4 \%$ ). In the treatment Group A and Group B, one to three packages were most often prescribed within the 12-month follow-up period $(41.8 \%$ and $53.6 \%$, respectively), but in contrast patients changing the prophylactic treatment had the highest proportion of "high-users" with about a quarter of them using more than 10 different prescribed packages $(25.6 \%$; Figure S1, Table S1).

\section{Discussion}

This retrospective cohort study provides a comprehensive picture of the treatment patterns in patients using triptan and prophylactic medication in daily clinical practice. We found a percentage of triptan users in the adult population of $1.3 \%$, whereby $17 \%$ of those were prescribed prophylactic treatments as well. Our prevalence is comparable with percentages of triptan users found in previous studies from the Netherlands $(1.0 \%)$, Italy $(0.7-1.0 \%)$, and France $(2.3 \%){ }^{11,14,17}$ Regarding the migraine-prophylactic medication, our finding is largely in line with previous studies. Based on our analysis, we found that most patients used triptans only, $4.5 \%$ of the patients combined triptans and prophylactic drugs, and $12.9 \%$ of the patients changed the treatment between triptan only and prophylactic use. 
Table 3 Sociodemographic and clinical characteristics of the patients by treatment patterns

\begin{tabular}{|c|c|c|c|c|}
\hline Characteristic & Triptan only (Group I) & Triptan and prophylactics (Group 2) & $\begin{array}{l}\text { Change in treatment } \\
\text { (Group 3) }\end{array}$ & $\begin{array}{l}P \text { - } \\
\text { value }\end{array}$ \\
\hline Total & $8,338(100 \%)$ & $454(100 \%)$ & $\mathrm{I}, 298(100 \%)$ & \\
\hline \multicolumn{5}{|l|}{ Gender } \\
\hline Female & $6,727(80.7 \%)$ & $355(78.2 \%)$ & $1,099(84.7 \%)$ & $* * *, \mathrm{a}$ \\
\hline Male & I,6II (19.3\%) & $99(21.8 \%)$ & $199(15.3 \%)$ & \\
\hline Mean age (SD) & $47.7(14.7)$ & $48.4(15.6)$ & $49.9(15.0)$ & $* * *, \mathrm{~b}$ \\
\hline \multicolumn{5}{|l|}{ Age group } \\
\hline 18-24 & $562(6.7 \%)$ & $36(7.9 \%)$ & $75(5.8 \%)$ & $* *^{a}$ \\
\hline $25-34$ & I, I34 (I3.6\%) & $6 \mathrm{I}(13.4 \%)$ & $142(10.9 \%)$ & \\
\hline $35-44$ & I,699 (20.4\%) & 91 (20.0\%) & $234(18.0 \%)$ & \\
\hline $45-54$ & $2,248(27.0 \%)$ & $107(23.6 \%)$ & $360(27.7 \%)$ & \\
\hline $55-64$ & $\mathrm{I}, 556(18.7 \%)$ & 89 (19.6\%) & $277(21.3 \%)$ & \\
\hline $65-74$ & 847 (10.2\%) & $47(10.4 \%)$ & $139(10.7 \%)$ & \\
\hline $75-84$ & $25 \mathrm{I}(3.0 \%)$ & $20(4.4 \%)$ & $60(4.6 \%)$ & \\
\hline$>84$ & $4 \mathrm{I}(0.5 \%)$ & $3(0.7 \%)$ & II (0.8\%) & \\
\hline \multicolumn{5}{|l|}{ Region } \\
\hline Mittelland & I,447 (I7.4\%) & $80(17.6 \%)$ & $266(20.5 \%)$ & $* * * a$ \\
\hline Northwest & I,245 (I4.9\%) & 61 (I3.4\%) & $186(14.3 \%)$ & \\
\hline East & $894(10.7 \%)$ & 45 (9.9\%) & $143(11.0 \%)$ & \\
\hline Leman & I,423 (I7.1\%) & $101(22.2 \%)$ & $224(17.3 \%)$ & \\
\hline Ticino & $476(5.7 \%)$ & $41(9.0 \%)$ & $106(8.2 \%)$ & \\
\hline Central & $692(8.3 \%)$ & $32(7.0 \%)$ & $86(6.6 \%)$ & \\
\hline Zurich & $2,161 \quad(25.9 \%)$ & $94(20.7 \%)$ & $287(22.1 \%)$ & \\
\hline \multicolumn{5}{|l|}{ Comorbidity status } \\
\hline Migraine only & I,I 82 (I4.2\%) & $20(4.4 \%)$ & $40(3.1 \%)$ & $* * * a$ \\
\hline Migraine with I CC & I,357 (I6.3\%) & $36(7.9 \%)$ & $100(7.7 \%)$ & \\
\hline Migraine with $2 \mathrm{CC}$ & I,508 (I8.1\%) & 70 (15.4\%) & 175 (13.5\%) & \\
\hline Migraine with $>2 \mathrm{CC}$ & 4,291 (5I.5\%) & $328(72.2 \%)$ & $983(75.7 \%)$ & \\
\hline Triptan use (previous year) & $4,337(52.0 \%)$ & $301(66.3 \%)$ & 799 (61.6\%) & $* * * a$ \\
\hline Prophylactics use (previous year) & $395(4.7 \%)$ & 302 (66.5\%) & $793(61.1 \%)$ & $* * * a$ \\
\hline \multicolumn{5}{|l|}{ Acute medication } \\
\hline Analgesics & $4,485(53.8 \%)$ & $300(66.1 \%)$ & $883(68.0 \%)$ & $*^{* * * * a}$ \\
\hline Antiemetics & $194(2.3 \%)$ & II (2.4\%) & $58(4.5 \%)$ & $*_{* * *}$ \\
\hline
\end{tabular}

Notes: ${ }^{\text {a }}$ Chi-square test; ${ }^{b}$ Kruskal-Wallis test. $* * P<0.01$, $* * * P<0.001$.

Abbreviation: CC, chronic condition.

Lafata et al. ${ }^{12}$ reported a percentage of $13-15 \%$ of patients receiving $\geq 2$ prescriptions for a medication with migraine preventive properties, whereas another study yielded a broader range from $14 \%$ to $21 \%$ of triptan users who were concurrently prescribed at least one prophylactic medication in a year. ${ }^{17}$ Overall, the preventive pharmacotherapy for migraine might be underutilized in clinical practice. This is surprising in light of the US, Canadian, and European guidelines for migraine prevention, supporting the use of prophylactic drugs as metoproplol or topiramate..$^{2,19,20}$
Our analysis also revealed that most patients who used "triptan and beta-blockers (only)" or "triptan and other prophylactics (eg, topiramate)" at the start of the treatment (first quarter) did not continue this treatment over all other quarters. Prophylactics were prescribed only at the start of therapy (first quarter) in a large number of cases $(25 \%)$. This finding indicates low adherence to migraine-preventive medication, which is in line with adherence rates as reported by Hepp et al. ${ }^{21}$ (about $20 \%$ at 12 months) or by Berger et al. $^{22}$ (29\% at 6 months), but other similar studies revealed higher adherence rates, as described by 

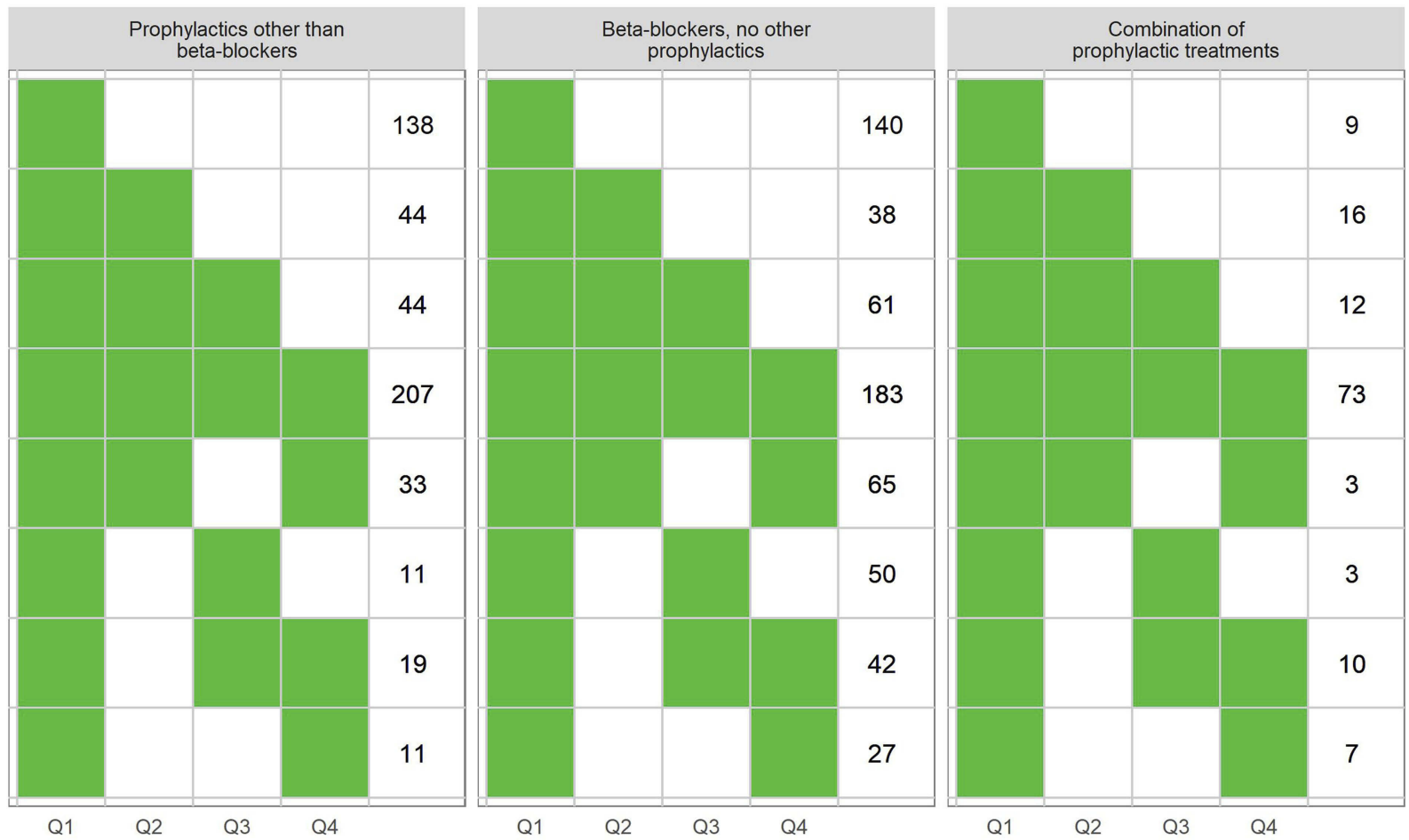

Figure 2 Type of prophylactic treatment in patients with use of triptan and prophylactics in QI (per quarter).

Lafata et al. ${ }^{12}$ (56\% at 12 months). Since studies differ in used active ingredients and observed time periods, it is quite difficult to compare with each other. We also found a small, but relevant proportion of patients combining triptan use with beta-blockers and other prophylactics at least once in the year, and moreover, most of them received both preventive drugs concomitantly over four quarters (55\%). Present analyses also revealed that some patients switched between several drug classes and were prescribed a high number of packages, which may indicate nonresponse to triptans and prophylactics. This might be caused by adverse effects, contraindications or intolerances. ${ }^{3,5}$ Therefore, our findings help to quantify the population who potentially use new approaches for the management of migraine therapy. This patient population includes 1) patients who stopped the prophylactic treatment within the first year, indicating that the acceptance of these drugs may be limited by these patients, 2) high users of prophylactics "beta-blockers" and "other prophylactics" concurrently over a year, and 3) patients who switched several times between various drug classes. In this context, the novel CGRP-targeted drugs seem to be promising as a new era of migraine therapy. Anti-CGRP drugs seem to be well tolerated. ${ }^{23}$ Furthermore, since triptan users represent the target population for novel CGRP antagonist consumers, our study provides data that enables forthcoming comparisons before and after the introduction of the new drug class.

This study has some limitations, which should be considered when interpreting the results. First, we analyzed the reimbursement of drugs. Prescriptions rates might be higher, and drug intake rates are likely to be lower. Second, there is a small proportion of medications that were not recorded in our database (eg, out-of-pocket payments). However, internal analysis estimated that this proportion is around $3 \%$ of total prescriptions, so that the potential bias is very small. ${ }^{24}$ Third, for technical reasons, we did not analyze the number of tablets per package, so that we cannot draw precise conclusions on the amount of drugs prescribed. Fourth, comorbidity was measured indirectly by medication claims. Fifth, the use of botulinum toxin was very low. Botulinum toxin for migraine is reimbursed only in very severe cases after medical examination and assessment of efficacy, appropriateness, and effectiveness in the individual case by the medical officer of the health insurance (Article 71a, Swiss health insurance regulation, KVV). Sixth, our database is not completely representative of the Swiss population as minor differences in sex, age, and regions exist. ${ }^{25}$ However, we are quite confident that our results are generalizable. The 


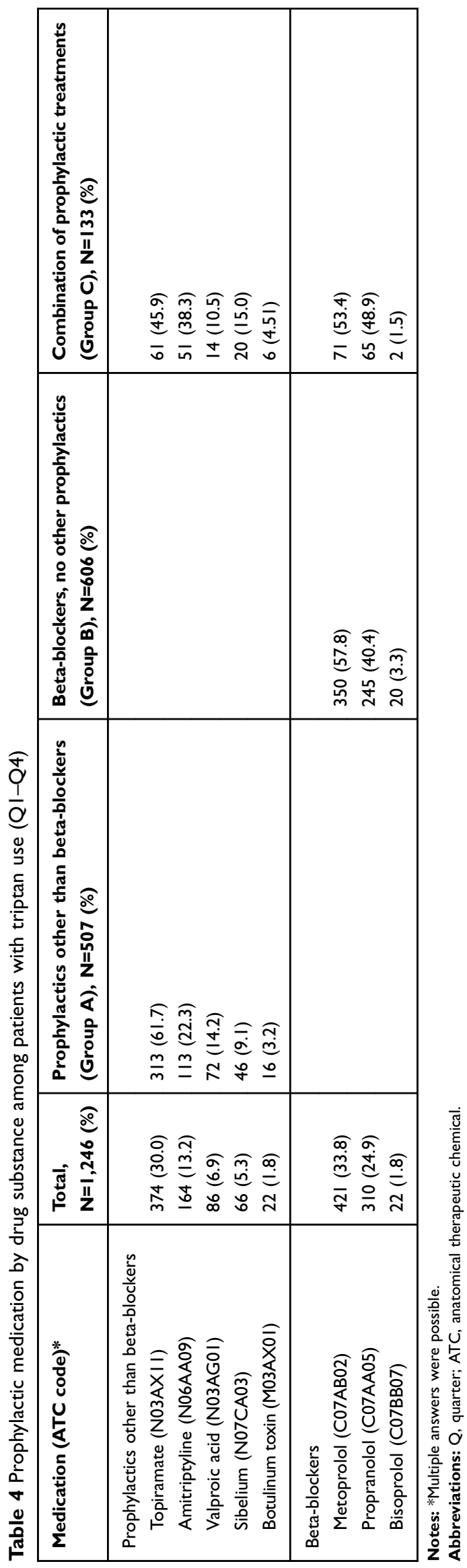

study was based on a population of more than one million persons from all Swiss regions, and the data had a high degree of completeness. ${ }^{26}$ Furthermore, the basic health insurance package is mandatory for all Swiss residents. Services provided in the basic health insurance are defined at national level, and thus equally valid for every health insurer. In addition, to our knowledge, this is the first study evaluating the current treatment patterns in patients using triptan and prophylactics before the introduction of CGRP antagonists, by analyzing health care claims from daily clinical practice. In contrast to data from clinical trials, claims data picture patients treated in a real-life setting including those with more heterogeneous characteristics, comorbidities, and concurrent drug use. Another strength is that we assessed the migraine treatment patterns in a timeframe of 12 months, divided into four quarters. In this way, we were able to provide more reliable and robust results compared to previous studies measuring only one time point.

\section{Conclusion}

The present study is a comprehensive claims-based analysis describing the treatment patterns in patients in need of medical treatment for migraine. The majority of triptan users had no prophylactic medication therapy; however, analyses also revealed a small, but relevant high user group having beta-blockers and other prophylactics during all four quarters. Results help to describe and quantify the migraine patient population that might potentially benefit from the novel CGRP-targeted drugs. This study provides the baseline for future evaluations after the introduction of CGRP antagonists.

\section{Acknowledgment}

Financial support for this study was provided by Novartis Pharma Switzerland AG. The sponsor had no role in collection, analysis, and interpretation of data; writing of the paper; or in the decision to submit the paper for publication.

\section{Disclosure}

Dr Carola A Huber reports grants from Novartis Pharma Switzerland AG, during the conduct of the study. Dr Eva Blozik reports grants from Novartis Pharma Switzerland, during the conduct of the study; grants from Vifor Pharma, grants from Amgen Switzerland, grants from MSD Switzerland, and grants from Astra Zenca, outside the submitted work. The authors report no other conflicts of interest in this work. 


\section{References}

1. Evers S, Afra J, Frese A, et al. EFNS guideline on the drug treatment of migraine-revised report of an EFNS task force. Eur J Neurol. 2009;16:968-981. doi:10.1111/j.1468-1331.2009.02748.x

2. Silberstein SD, Holland S, Freitag F, Dodick DW, Argoff C, Ashman E. Evidence-based guideline update. Pharmacologic treatment for episodic migraine prevention in adults: report of the quality standards subcommittee of the American academy of neurology and the American headache society. Neurology. 2012;78:1337-1345. doi:10.1212/WNL.0b013e3182535d20

3. Linde K, Allais G, Brinkhaus B, et al. Acupuncture for the prevention of episodic migraine. Cochrane Database Syst Rev. 2016:CD001218. doi:10.1002/14651858.CD001218.pub3.

4. Linde M, Mulleners WM, Chronicle EP, McCrory DC. Topiramate for the prophylaxis of episodic migraine in adults. Cochrane Database Syst Rev. 2013;CD010610. doi:10.1002/14651858.CD010610

5. Goadsby PJ, Lipton RB, Ferrari MD. Migraine-current understanding and treatment. $N$ Engl $J$ Med. 2002;346:257-270. doi:10.1056/ NEJMra010917

6. Goadsby PJ, Reuter U, Hallström Y, et al. A controlled trial of erenumab for episodic migraine. $N$ Engl J Med. 2017;377:21232132. doi:10.1056/NEJMoa1705848

7. Dodick DW, Ashina M, Brandes JL, et al. ARISE: a phase 3 randomized trial of erenumab for episodic migraine. Cephalalgia. 2018;38:1026-1037. doi:10.1177/0333102418759786

8. Tepper S, Ashina M, Reuter U, et al. Safety and efficacy of erenumab for preventive treatment of chronic migraine: a randomised, doubleblind, placebo-controlled phase 2 trial. Lancet Neurol. 2017;16:425434. doi:10.1016/S1474-4422(17)30083-2

9. Doods H, Hallermayer G, Wu D, et al. Pharmacological profile of BIBN4096BS, the first selective small molecule CGRP antagonist. $\mathrm{Br}$ J Pharmacol. 2000;129:420-423. doi:10.1038/sj.bjp.0703110

10. Holland PR, Goadsby PJ. Targeted CGRP small molecule antagonists for acute migraine therapy. Neurotherapeutics. 2018;15:304-312. doi:10.1007/s13311-018-0617-4

11. Smelt AFH, Assendelft WJJ, van Dijk CE, Blom JW. Triptan use after starting prophylactic migraine treatment: a retrospective cohort study in a primary care population. Cephalalgia. 2014;34:927-932. doi:10.1177/0333102414521511

12. Lafata JE, Tunceli O, Cerghet M, Sharma KP, Lipton RB. The use of migraine preventive medications among patients with and without migraine headaches. Cephalalgia. 2010;30:97-104. doi:10.1111/ j.1468-2982.2009.01909.x

13. Hepp Z, Bloudek LM, Varon SF. Systematic review of migraine prophylaxis adherence and persistence. J Manag Care Spec Pharm. 2014;20:22-33. doi:10.18553/jmcp.2014.20.1.22
14. Braunstein D, Donnet A, Pradel V, et al. Triptans use and overuse: a pharmacoepidemiology study from the French health insurance system database covering 4.1 million people. Cephalalgia. 2015;35:1172-1180. doi:10.1177/0333102415570497

15. Zebenholzer K, Gall W, Wöber C. Use and overuse of triptans in Austria - a survey based on nationwide healthcare claims data. $J$ Headache Pain. 2018;19:34. doi:10.1186/s10194-018-0864-0

16. Dekker F, Wiendels NJ, de Valk V, et al. Triptan overuse in the Dutch general population. A nationwide pharmaco-epidemiology database analysis in 6.7 million people. Cephalalgia. 2011;31:943-952. doi:10.1177/0333102411408626

17. Da Cas R, Nigro A, Terrazzino S, et al. Triptan use in Italy: insights from administrative databases. Cephalalgia. 2015;35:619-626. doi:10.1177/0333102414550419

18. Huber CA, Szucs TD, Rapold R, Reich O. Identifying patients with chronic conditions using pharmacy data in Switzerland: an updated mapping approach to the classification of medications. BMC Public Health. 2013;13:1030. doi:10.1186/1471-2458-13-1030

19. Pringsheim T, Davenport WJ, Mackie G, Worthington IM. Canadian headache society guideline for migraine prophylaxis: supplement 2. Can J Neurol Sci. 2012;39:i-63. doi:10.1017/ S0317167100015109

20. Carville S, Padhi S, Reason T, Underwood M. Diagnosis and management of headaches in young people and adults: summary of NICE guidance. BMJ. 2012;345:e5765. doi:10.1136/bmj.e5765

21. Hepp Z, Dodick DW, Varon SF, Gillard P, Hansen RN, Devine EB. Adherence to oral migraine-preventive medications among patients with chronic migraine. Cephalalgia. 2015;35:478-488. doi:10.1177/ 0333102414547138

22. Berger A, Bloudek LM, Varon SF, Oster G. Adherence with migraine prophylaxis in clinical practice. Pain Pract. 2012;12:541-549. doi:10.1111/j.1533-2500.2012.00530.x

23. Edvinsson L. Headache advances in 2017. A new horizon in migraine therapy. Lancet Neurol. 2018;17:5-6. doi:10.1016/S1474-4422(17) 30415-5

24. Reich O, Rapold R, Thöni M. An empirical investigation of the efficiency effects of integrated care models in Switzerland. Int $J$ Integr Care. 2012;12. doi:10.5334/ijic.685.

25. Huber CA, Schwenkglenks M, Rapold R, Reich O. Epidemiology and costs of diabetes mellitus in Switzerland: an analysis of health care claims data, 2006 and 2011. BMC Endocr Disord. 2014;14:44. doi:10.1186/1472-6823-14-44

26. Huber CA, Schneeweiss S, Signorell A, Reich O. Improved prediction of medical expenditures and health care utilization using an updated chronic disease score and claims data. J Clin Epidemiol. 2013;66:1118-1127. doi:10.1016/j.jclinepi.2013.04.011 


\section{Supplementary materials}

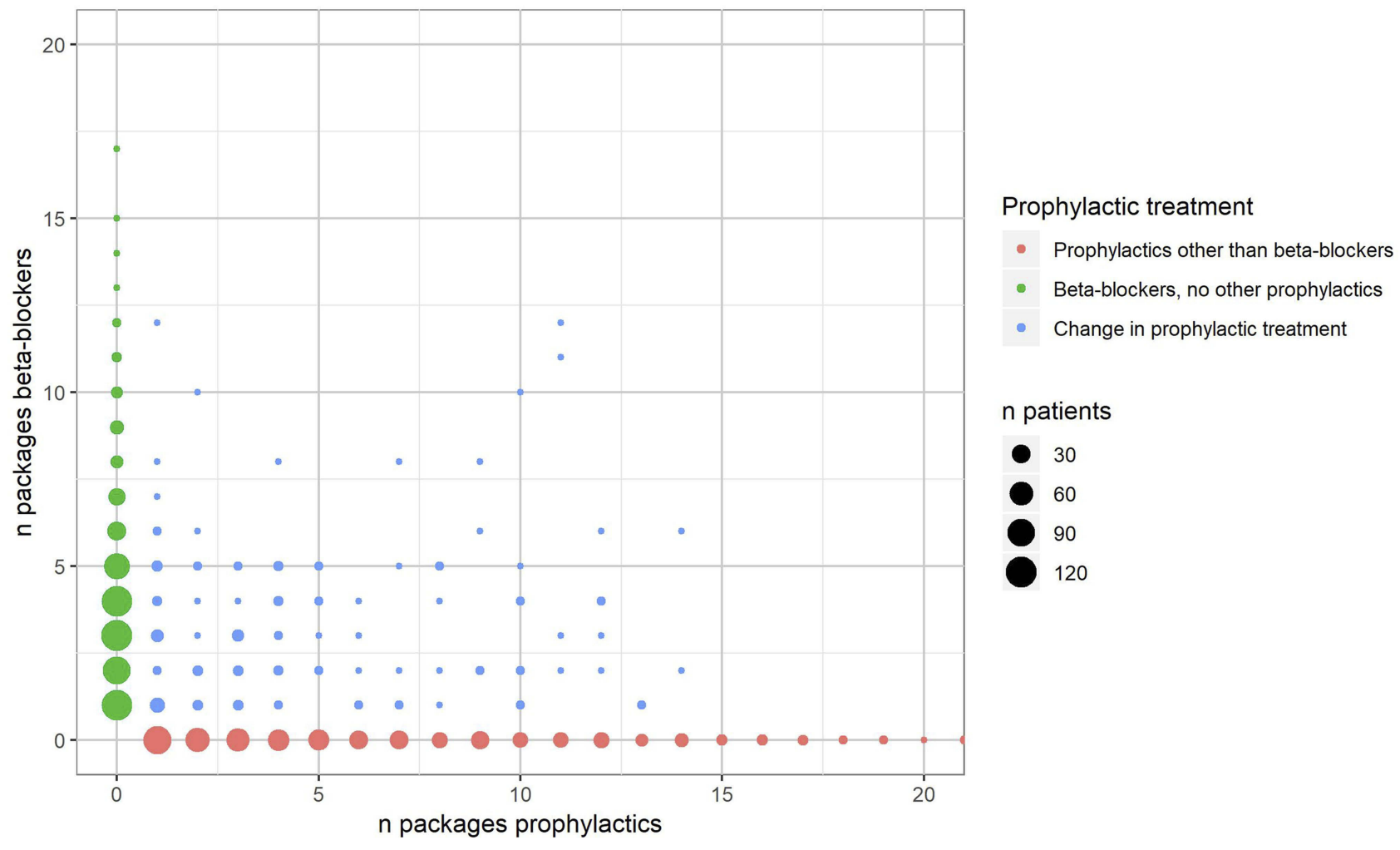

Figure SI Medication use of the prophylactic groups. 
Table SI Number of patients and packages by prophylactic group (QI-Q4)

\begin{tabular}{|c|c|c|c|}
\hline $\begin{array}{l}\text { Number of } \\
\text { packages }\end{array}$ & $\begin{array}{l}\text { Prophylactics other than beta- } \\
\text { blockers (Group A) } \\
\text { N }\end{array}$ & $\begin{array}{l}\text { Beta-blockers, no other prophy- } \\
\text { lactics (Group B) } \\
\text { N }\end{array}$ & $\begin{array}{l}\text { Combination of prophylactic treat- } \\
\text { ments (Group C) } \\
\text { N }\end{array}$ \\
\hline I & 93 & 113 & 0 \\
\hline 2 & 63 & 91 & 15 \\
\hline 3 & 56 & 121 & 6 \\
\hline 4 & 47 & 113 & 17 \\
\hline 5 & 41 & 78 & 10 \\
\hline 6 & 32 & 32 & 16 \\
\hline 7 & 31 & 23 & 11 \\
\hline 8 & 19 & 8 & 11 \\
\hline 9 & 27 & 11 & 9 \\
\hline 10 & 17 & 6 & 4 \\
\hline II & 17 & 3 & 4 \\
\hline 12 & 19 & 2 & 6 \\
\hline 13 & 9 & I & 4 \\
\hline 14 & 11 & I & 6 \\
\hline 15 & 5 & I & 4 \\
\hline 16 & 5 & 0 & 3 \\
\hline 17 & 4 & I & I \\
\hline 18 & 2 & 0 & 1 \\
\hline 19 & 2 & 0 & 0 \\
\hline 20 & I & 0 & 2 \\
\hline 21 & 2 & 0 & 0 \\
\hline 22 & 0 & 0 & I \\
\hline 23 & I & I & I \\
\hline 26 & I & 0 & 0 \\
\hline 28 & I & 0 & 0 \\
\hline 30 & I & 0 & 0 \\
\hline$>30$ & 0 & 0 & I \\
\hline
\end{tabular}

\section{Publish your work in this journal}

The Journal of Pain Research is an international, peer reviewed, open access, online journal that welcomes laboratory and clinical findings in the fields of pain research and the prevention and management of pain. Original research, reviews, symposium reports, hypothesis formation and commentaries are all considered for publication. The manuscript management system is completely online and includes a very quick and fair peer-review system, which is all easy to use. Visit http:// www.dovepress.com/testimonials.php to read real quotes from published authors. 